Original Research Paper

\title{
Experimental Comparisons of Anchovy Drying using Centrifugal and Gravitational Fluidized Bed Techniques
}

\author{
${ }^{1}$ Watcharin Dongbang and ${ }^{2}$ Rungtawan Wiwattanasirikul \\ ${ }^{I}$ Department of Mechanical Engineering, Faculty of Engineering, Burapha University, Thailand \\ ${ }^{2}$ Department of Mechanical Engineering, Faculty of Engineering, Chaiyaphum Rajabhat University, Thailand
}

\author{
Article history \\ Received: 12-03-2015 \\ Revised: 25-03-2015 \\ Accepted: 28-03-2015 \\ Corresponding Author: \\ Watcharin Dongbang \\ Department of Mechanical \\ Engineering, Faculty of \\ Engineering, Burapha \\ University, Thailand \\ Email: dr.watcharin@gmail.com
}

\begin{abstract}
The present study investigated experimental comparisons of anchovy drying using centrifugal and gravitational fluidized bed techniques; in addition, drying models and thermal efficiency were also investigated. In the first stage, fresh anchovy was dried with solar energy to reduce the initial moisture content from $81 \pm 1 \% \mathrm{wb}$ to around $65 \% \pm 1 \mathrm{wb}$. In the second stage, the anchovy was dried with a dryer from $65 \pm 1 \% \mathrm{wb}$ to around $10 \% \pm 1 \mathrm{wb}$. The drying air flow rates for drying with the centrifugal fluidized bed dryer and gravitational fluidized bed dryer were fixed at $0.27 \pm 0.01$ and $0.12 \pm 0.01^{-1}$ respectively. The hot air temperatures for drying were in the range $60-80^{\circ} \mathrm{C}$. Drying times for anchovy with the centrifugal fluidized bed dryer and gravitational fluidized bed dryer were 86-153 and 79-135 min. respectively. The increase in drying temperature is a significant factor in decreasing the moisture and darkness of dried anchovy. The quality of the dried anchovy is acceptable. The Page's drying model is the best model based on the highest value of $\mathrm{R}^{2}$ and the lowest value of RMSE.
\end{abstract}

Keywords: Anchovy, Drying Kinetics, Drying Model, Energy Efficiency, Fluidized Bed

\section{Introduction}

Anchovy is known by different names in different parts of the world. It can be found in the Atlantic, Indian, Pacific Oceans, Black Sea, Mediterranean Sea and Gulf of Thailand (Dongbang and Matthujak, 2013; Basilone et al., 2015). Anchovy is a small fish that can be cooked many different ways and can be preserved by drying. Initial moisture content of fresh anchovy is very high (Marina and Maria, 2013). It is reduced by drying with a dryer or solar power. The different drying mechanisms affect the energy cost, drying time and quality. Products dried by solar power may be contaminated with dust, dirt, rainfall, animals, birds, rodents, insects and microorganisms and also take longer (Travis et al., 2013). Fluidized bed dryers are one of the hot air dryers that show a high rate of heat and mass transfer (Chok et al., 2010). They consist of a vertical drying chamber and the products are dried in high velocity hot air which is supplied by a blower (Ghaly et al., 2012). Fluidization techniques had been applied in many industries (Rieck et al., 2015), i.e., micro-granulation of fine powders, coaters, nano- agglomerates, etc. Up to now, this drying technique has been adapted for drying agricultural products such as soybean and paddy (Chungcharoen et al., 2014) which mostly have a near spherical shape. Wet cylindrical products which need to be dried have few reports about drying kinetics with fluidized bed dryers which is important data for developing dryers.

The objectives of this research as follows; (i) to experimentally compare the drying kinetics of anchovy by using the centrifugal fluidized bed and gravitational fluidized bed dryer and (ii) to develop mathematical drying models.

\section{Materials and Methods}

\section{Moisture Content}

The moisture content of products is used as a parameter of maturity and is expressed as a percentage of moisture based on Wet Basis (WB) or Dry Basis (DB). In this study, the moisture content of anchovy with wet basis was determined by the AOAC method (AOAC, 1998) and can be calculated as in Equation 1: 


$$
M_{i n}=\left(\frac{m_{w}-m_{d}}{m_{w}}\right) 100 \%
$$

Where:

$\mathrm{m}_{\mathrm{w}}=$ The wet weight

$\mathrm{m}_{\mathrm{d}}=$ The dry weight and

$\mathrm{M}_{\text {in }}=$ The moisture content on a percentage basis

The average initial moisture content of anchovy was found to be around $81 \pm 1 \%$ wb.

\section{Drying Stages}

After pre-testing Gravitational Fluidized Bed (GFB) dryers it was found that the anchovy could not be fluidized at moisture content higher than $65 \pm 1 \% \mathrm{wb}$. Drying with solar was selected for pre-drying in the first stage and GFB and Centrifugal Fluidized Bed (CFD) dryers were used in the second stage. The drying stages are shown in Fig. 1.

The fresh anchovies were maintained in ice from capture until arriving in the laboratory. They were washed clean and sized from $5 \pm 1 \mathrm{~cm}$ in length. The samples were put in gratings for drying with solar power (Fig. 2). The moisture content before and after drying was calculated using Equation 1. The drying was carried out on a clear day and moisture content dropped until around $65 \% \mathrm{wb}$. The damp anchovy after drying with solar power were separated into two samples for drying with the two fluidized bed dryers. The final moisture dropped from around $65 \% \pm 1 \mathrm{wb}$ to around $10 \% \pm 1 \mathrm{wb}$ by the CFB dryer (Fig. 3a) and the GFB dryer (Fig. 3b). The conditions were three intervals of air temperature, namely 60,70 and $80^{\circ} \mathrm{C}$ at minimum fluidized bed velocity by type of dryer.

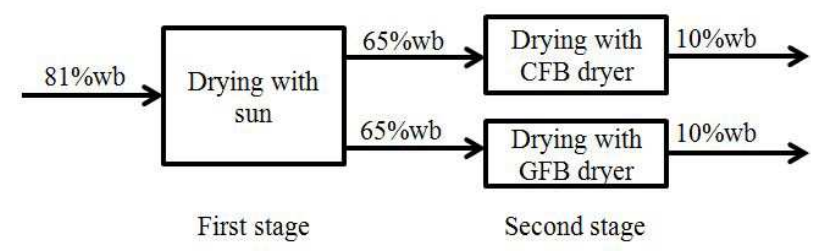

Fig. 1. Anchovy drying stage diagram

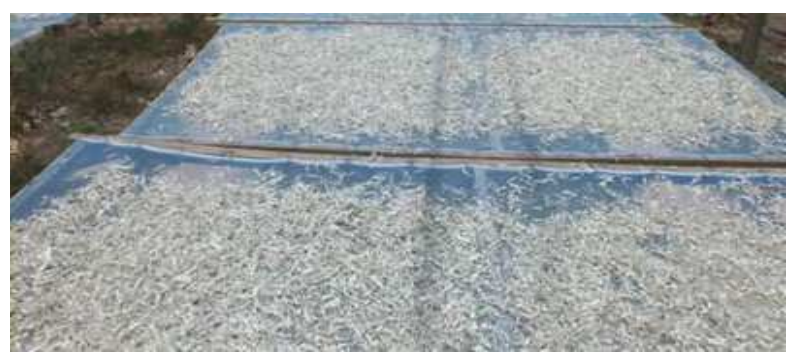

Fig. 2. Anchovy drying in the sun

\section{CFB Technique}

The particles and hot air interaction in Fig. 4 show the forces acting such as centrifugal force $\left(F_{c}=m_{p} r \omega^{2}\right)$ and gravitational force $\left(F_{g}=m_{p} g\right)$. The dryer consists of a cylindrical plenum chamber and a porous walled cylindrical air-distributor which rotates around the axis of the drying chamber. When the air-distributor rotates, the anchovies are forced to move towards the rotating air-distributor surface by the centrifugal force and form annular layers. While air flows inward through the air-distributor wall, the anchovy position will be balanced by drag force and centrifugal force (Triratanasirichai et al., 2011). Pressure drop $\left(\Delta P_{f}\right)$ and minimum fluidization velocity $\left(U m_{f}\right)$ are very important for designing and controlling the dryer. Kao has developed the method for calculating using Equation 2 (Nakamura and Watano, 2007):

$$
\Delta P_{f}=0.5(1-\varepsilon)\left(\rho_{p}-\rho_{f}\right) \frac{G g}{r_{o}}\left(r_{o}^{2}-r_{i}^{2}\right)
$$

Where:

$\Delta P_{f}=$ The pressure drop in the fluidized bed

$\varepsilon \quad=$ The voidage fraction of the particle phase

$p_{p}=$ The bulk density of particles

$p_{f}=$ The air density

$r_{o}=$ The outer radius of the bed

$\eta \quad=$ The inner radius of the bed

$G=$ The ratio of centrifugal acceleration and

$g \quad=$ The gravitational acceleration

The pressure drop was found to equal $522 \mathrm{~Pa}$ based on the ratio $G=2.5$. The equation for calculating the minimum air velocity can be seen in the following Equation 3 (Nakamura and Watano, 2007):

$$
U_{m f}=\frac{\mu_{f}}{d_{p} \rho_{f}}\left(\left\{(33.7)^{2}+0.0408 G a\right\}^{0.5}-33.7\right)
$$

Given:

$G a=\frac{\rho_{f}\left(\rho_{p}-\rho_{f}\right) G g d_{p}^{3}}{\mu_{f}^{2}}$

Where:

$U_{m f}=$ The minimum air velocity

$\mu_{f}=$ The gas viscosity (dynamic) and

$d_{p}=$ The particle diameter

The minimum air velocity was found to equal 2.2 $\mathrm{ms}^{-1}$. The apparatus (Fig. 5) once used to dry chili (Dongbang et al., 2010) consists of a blower used to supply air into a centrifugal drying chamber (No.1) and the air flow rates were varied by frequency invertors. 


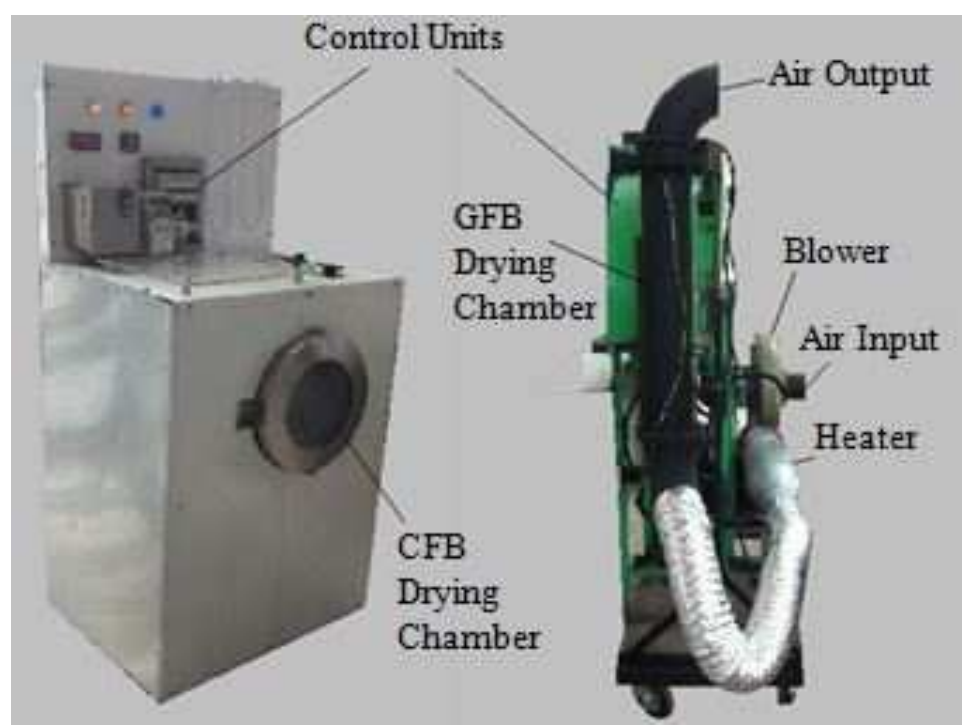

(a) (b)

Fig. 3. Fluidized bed dryer (a) CFB dryer (b) GFB dryer

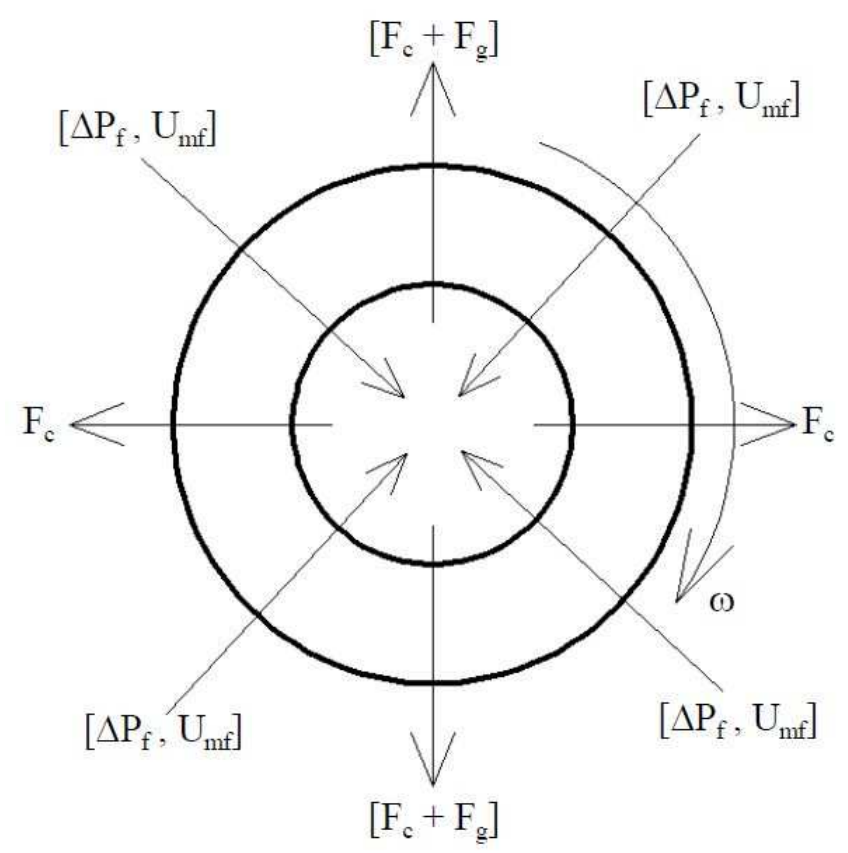

Fig. 4. Balancing forces in a CFB dryer

Drying air was heated by an electrical heater (No.2) which was controlled by a PID controller to an accuracy of $\pm 1{ }^{\circ} \mathrm{C}$. Air flow rates were measured by U-tube manometer (No.3) in conjunction with an orifice plate. Samples of anchovy were dried in the drying chamber (No.4). The bed of anchovies (No.5) was fluidized after rotating the drying chamber. Hot air was ventilated through the filter (No.6). The drying chamber (No.4) was rotated by electrical motor (No.7) and behavior of fluidization was recorded by high speed camera (No.8).
The pressure drop was measured by U-tube manometer (No.9). The exhaust air (No.10) was partially recycled through the recycling duct (No.11). The air temperature and flow rate can be adjusted at the bypass duct (No.12). The apparatus was operated with a time of $30 \mathrm{~min}$. for stabilizing the drying conditions. About $500 \mathrm{~g}$ samples were filled into the drying chamber. Finally, the moisture loss was recorded every $10 \mathrm{~min}$ during the drying process. The experiments were repeated three times and the average data was evaluated for analysis. 


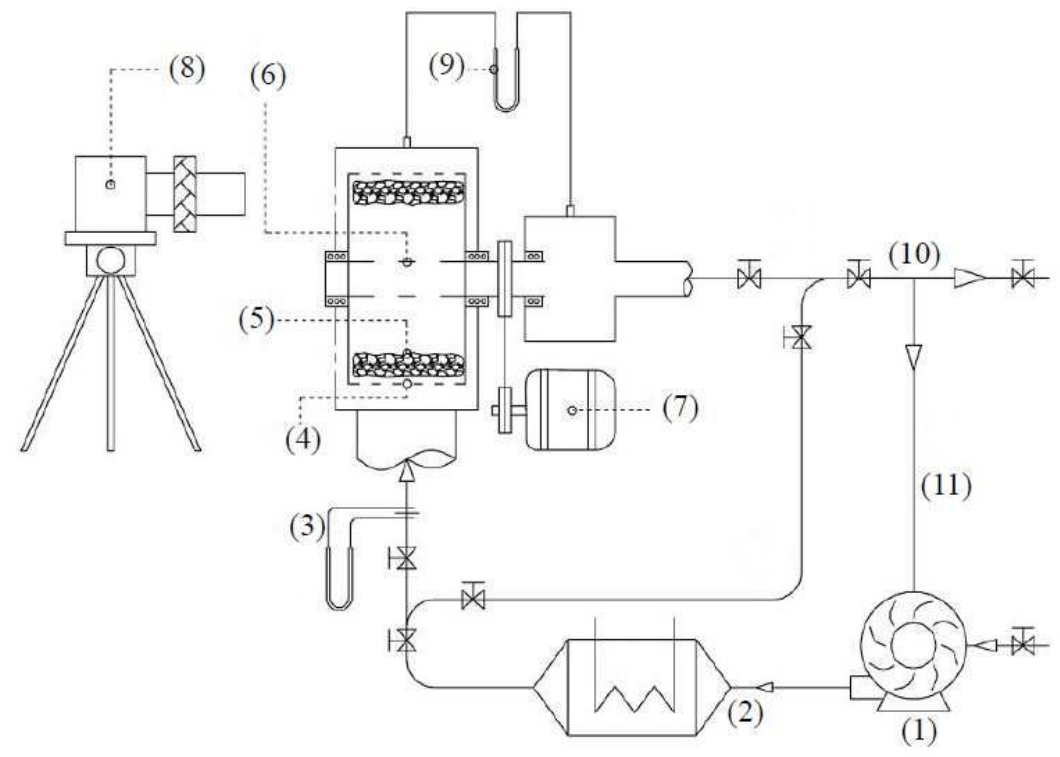

Fig. 5. Schematic diagram of CFB dryer

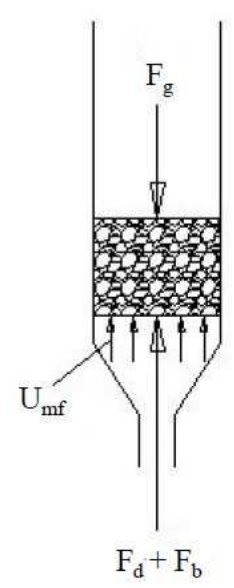

(a)

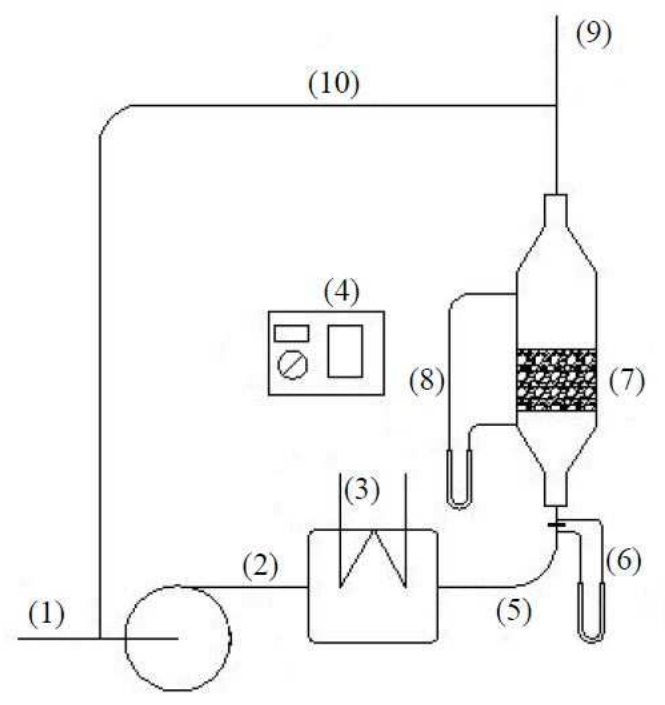

(b)

Fig. 6. Apparatus diagram of a GFB dryer (a) Balancing forces (b) Schematic diagram

\section{GFB Technique}

The incipient point at which the gas flow causes the bed of particles to expand and lift into the vertical column is marked by a conceptually simple balance i.e., drag forces $\left(F_{d}\right)$, gravitational forces $\left(F_{g}\right)$ and buoyancy forces $\left(F_{o}\right)$. The balance must be performed on the entire bed of particles as shown in Fig. 6a. Modeling of the bed pressure drop $\left(\Delta P_{f}\right)$ and minimum fluidization velocity $\left(U_{m f}\right)$ in the gravitational fluidized bed has been developed by (Sau et al., 2007) as in Equation 5 and 6:

$$
\begin{aligned}
& \frac{\Delta P_{f}}{L}=150 \frac{(1-\varepsilon)^{2}}{\varepsilon^{3}} \frac{\mu U_{m f}}{d_{p}^{2}}+1.75 \frac{(1-\varepsilon)}{\varepsilon^{3}} \frac{\rho_{f} U_{m f}^{2}}{d_{p}} c \\
& U_{m f}^{2}=\frac{\phi_{p} d_{p}}{1.75} \frac{\left(\rho_{p}-\rho_{f}\right)}{\rho_{f}} g \varepsilon^{3} \operatorname{Re}>1000
\end{aligned}
$$

\section{Where:}

$\Delta P_{f}=$ The pressure drop

$\varepsilon=$ The voidage fraction of the particle phase

$\rho_{p}=$ The bulk density of particles 
$\rho_{f}=$ The air density

$U_{m f}=$ The minimum air velocity

$\mu_{f}=$ The gas viscosity (dynamic)

$d_{p}=$ The particle diameter

$g=$ The gravity acceleration and

$\phi_{p}=$ The volume fraction of the bed

The pressure drop and minimum velocity were found to be $825 \mathrm{~Pa}$ and $5.5 \mathrm{~ms}^{-1}$, respectively.

The apparatus (Fig. 6b) consists of fresh air (No.1) blown by a blower (No.2). The drying air was heated by an electrical heater (No.3) which was controlled by a PID controller (No.4) at accuracy of $\pm 1^{\circ} \mathrm{C}$. Air flow rates (No.5) were measured by U-tube manometer (No.6) in conjunction with the orifice plate. The bed of anchovy (No.5) was fluidized by blowing high pressure air to the drying chamber. The pressure drop was measured by Utube manometer (No.8). The exhaust air (No.9) was partially recycled through the recycling duct (No.10).

\section{Results}

\section{Fluidization Behavior}

The anchovy in the CFD dryer was initially fluidized at a rotating speed of $125 \pm 2 \mathrm{rpm}$, while the pressure drop was $546 \pm 2 \mathrm{~Pa}$ and the minimum air flow rate was $0.27 \pm 0.01 \mathrm{~kg} \cdot \mathrm{s}^{-1}$. The pressure drop had an error around $5 \%$ compared with the value calculated with Equation 2. For the case of anchovy in the GFD dryer, the initial fluidization occurred at a pressure drop of $858 \pm 2 \mathrm{~Pa}$, while the minimum air flow rate was $0.12 \pm 0.01 \mathrm{~kg} . \mathrm{s}^{-1}$. The pressure drop had an error of around 4\% compared to the value calculated by Equation 5 . The different size of anchovy gave an error in calculation. The minimum fluidization can be achieved at any gas flow rate by changing the rotating speed of the blower. The above described conditions were used for drying.

\section{Drying Kinetics}

The results were compared between CFD and GFD techniques based on identical air temperatures, namely 60,70 and $80^{\circ} \mathrm{C}$. The experimental Moisture Ratios (MR) were calculated using Equation 7 (Zhu and Shen, 2014):

$$
M R=\frac{M_{t}-M_{e}}{M_{i n}-M_{e}}
$$

Where:

$$
\begin{array}{ll}
M R & =\text { The moisture ratio } \\
M_{t} & =\text { The moisture content at any time and } \\
M_{i n} \text { and } M_{e}= & \text { Initial and equilibrium moisture contents, } \\
& \text { respectively }
\end{array}
$$

The moisture contents and moisture ratios were calculated by Equation 1 and 7 and are shown in Fig. 7 and 8 , respectively. The results to dry anchovy from $65 \pm 1 \%$ wb of the initial moisture content down to $10 \pm 1 \%$ wb with GFB and CFB dryers were 86-153 and 79-135 min. respectively, as shown in Fig. 9.

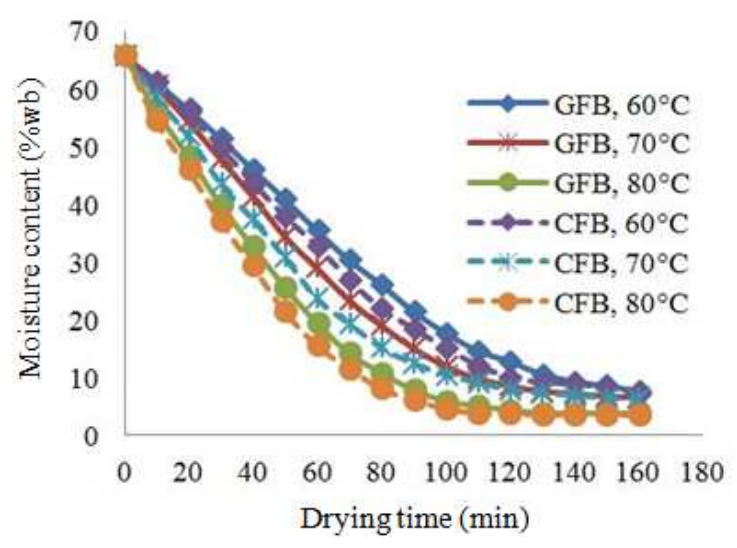

Fig. 7. Moisture ratio Vs drying time of CFB dryer

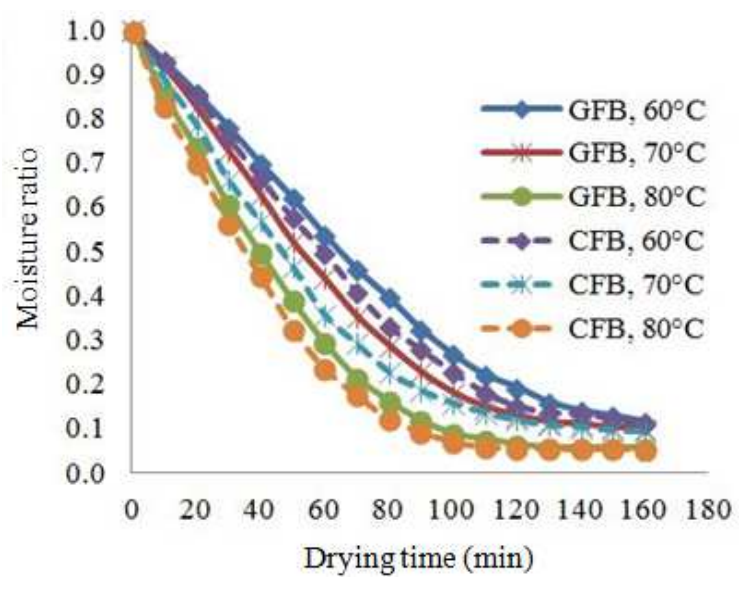

Fig. 8. Moisture ratio Vs drying time of GFB dryer

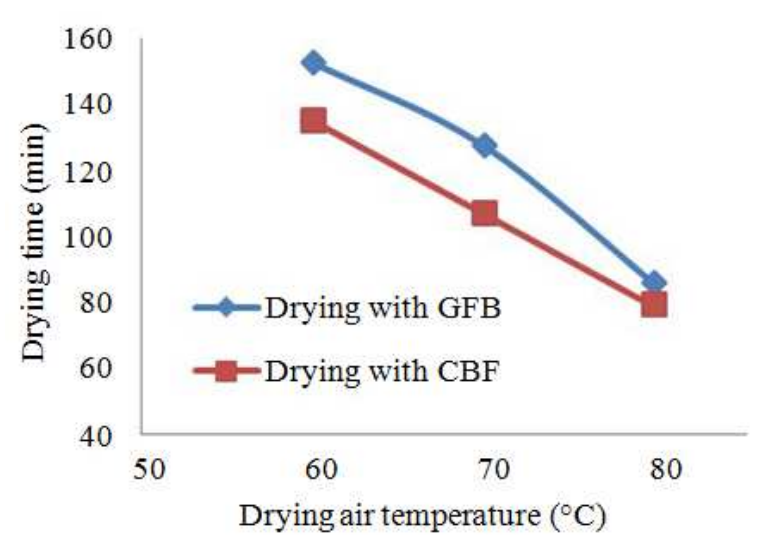

Fig. 9. Drying time to dry anchovy 
Table 1. Mathermatical drying models

\begin{tabular}{ll}
\hline Models & Model equation \\
\hline Newton & $\mathrm{MR}=\exp (-\mathrm{kt})$ \\
Page & $\mathrm{MR}=\exp \left(-\mathrm{kt} \mathrm{t}^{\mathrm{n}}\right)$ \\
Henderson & $\mathrm{MR}=\mathrm{a} \exp (-\mathrm{kt})$ \\
Lograrithmic & $\mathrm{MR}=\mathrm{a} \exp (-\mathrm{kt})+\mathrm{b}$ \\
Wang and singh & $\mathrm{MR}=1+\mathrm{at}+\mathrm{bt} \mathrm{t}^{\mathrm{n}}$ \\
\hline
\end{tabular}

Table 2. Parameters of mathermatical drying models in Table 1

\begin{tabular}{ll}
\hline Model & Parameters of model \\
\hline Newton & $\mathrm{k}=0.00040 \mathrm{~T}-0.01259$ \\
$\mathrm{k}=0.00046 \mathrm{~T}-0.01512^{*}$ \\
$\mathrm{k}=0.0003 \mathrm{~T}-0.014$ \\
$\mathrm{k}=0.0004 \mathrm{~T}-0.021^{*}$ \\
$\mathrm{n}=-0.0061 \mathrm{~T}+1.7118$ \\
$\mathrm{n}=-0.0072 \mathrm{~T}+1.7256^{*}$ \\
Henderson & $\mathrm{k}=0.0004 \mathrm{~T}-0.0115$ \\
& $\mathrm{k}=0.0004 \mathrm{~T}-0.0128^{*}$ \\
& $\mathrm{a}=-0.0012 \mathrm{~T}+1.1569$ \\
Lograrithmic & $\mathrm{a}=-0.002 \mathrm{~T}+1.1958^{*}$ \\
& $\mathrm{k}=0.0006 \mathrm{~T}-0.0252$ \\
& $\mathrm{k}=0.0006 \mathrm{~T}-0.0255^{*}$ \\
& $\mathrm{a}=-0.0121 \mathrm{~T}+2.0268$ \\
& $\mathrm{a}=-0.0079 \mathrm{~T}+1.6558^{*}$ \\
Wang and singh & $\mathrm{b}=0.0123 \mathrm{~T}-0.9935$ \\
& $\mathrm{~b}=0.0073 \mathrm{~T}-0.5636^{*}$ \\
& $\mathrm{a}=-0.0003 \mathrm{~T}+0.0081$ \\
& $\mathrm{a}=-0.0003 \mathrm{~T}+0.0069^{*}$ \\
& $\mathrm{~b}=2 \mathrm{E}-06 \mathrm{~T}-9 \mathrm{E}-05$ \\
& $\mathrm{~b}=2 \mathrm{E}-06 \mathrm{~T}-8 \mathrm{E}-05^{*}$
\end{tabular}

Note: *Indicates parameters for the CFB dryer while other parameters are for the GFB dryer

Table 3. Evalution of parameters for Table 2

\begin{tabular}{lll}
\hline Model & RSME & $\mathrm{R}^{2}$ \\
\hline Newton & 0.032712 & 0.978 \\
Page & $0.025981^{*}$ & $0.983^{*}$ \\
& 0.002233 & 0.998 \\
Henderson & $0.004715^{*}$ & $0.996^{*}$ \\
& 0.021631 & 0.985 \\
Lograrithmic & $0.018275^{*}$ & $0.987^{*}$ \\
& 0.013955 & 0.991 \\
Wang and singh & $0.015169^{*}$ & $0.989^{*}$ \\
& 0.007559 & 0.995 \\
& $0.009364^{*}$ & $0.994^{*}$ \\
\hline
\end{tabular}

Note: RMSE are root mean square error, *indicates parameters for the CFB dryer while other parameters are for the GFB dryer

\section{Drying Models}

The moisture ratios for thin-layer drying were fitted with the well-known models shown in Table 1 (Zhu and Shen, 2014).

Non-linear regression was used to determine the parameters, i.e., a, b, k and b. The effectiveness of models was evaluated via the statistical criteria such as coefficient of determination, $\mathrm{R}^{2}$ and Root Mean Square Error (RMSE). All parameters were calculated by software using the Statistical Package for the Social Sciences (SPSS). For the proposed model, the optimum condition with highest value of $\mathrm{R}^{2}$ and the lowest value of RMSE was selected. Analysis of variance was carried out to find the effect of drying air temperature. The parameters in Table 1 were found and are shown in Table 2 and 3.

The results from the Table 3 show the highest value of $\mathrm{R}^{2}$ in the Page's model; in addition, RMSE are lower than other models. These equations can be used to predict the various parameters of models within a Temperature $(\mathrm{T})$ range of $60-80^{\circ} \mathrm{C}$. The Page model is the best model based on the highest value of $\mathrm{R}^{2}$ and the lowest value of RMSE.

\section{Discussion}

The drying kinetics of anchovy were investigated based on identical air temperatures; on the other hand, different air flow rates were fixed based on the kind of dryer, namely, $0.27 \pm 0.01 \mathrm{~kg} . \mathrm{s}^{-1}$ for CFB dryer and $0.12 \pm 0.01 \mathrm{~kg} . \mathrm{s}^{-1}$ for GFD dryer. Figure 6 and 7 show the experimental drying curves of average Moisture Ratio (MR) versus drying time with CFB and GFB dryers, respectively. The curves show the influence of air temperature on the ability to reduce moisture. The drying air temperature affects the resistance of moisture movement at the surface. After increasing the air temperature from 60 to $80^{\circ} \mathrm{C}$, the latent heat was intensified and evaporation from the moist product is improved. While the moisture is high, the drying rate is very high and as the moisture content approaches the equilibrium moisture content, the drying rate is very low. The drying time is shown in Fig. 9 based on the final moisture content of $10 \% \mathrm{wb}$. The shortest time to dry anchovy can be found from the CFB dryer based on identical air temperatures.

The sensible heating processes relative to grain condition can be represented conveniently on the psychrometric chart. During sensible heating of air at constant humidity ratio, heat is added to the drying air by a heater. The heat required for evaporation of the grain moisture is supplied solely by the drying air as an adiabatic process. As the air passes through the wet grain mass, a larger part of the sensible heat of the air is transferred into latent heat as result of the increasing amount of water held in the air as vapor. During the adiabatic drying process there is a decrease in the dry-bulb temperature, together with an increase in the humidity ratio. The enthalpy and wet-bulb temperature remain practically constant during the adiabatic drying process (Mujumdar, 2000). The illustration of drying process based on the psychrometric chart is shown in Fig. 10. The energy used for moisture evaporation and total energy given to the dryer was used to evaluate the thermal efficiency using Equation 8 and 9 (Mujumdar, 2000):

$\eta=\frac{\text { Energy used for moisture evaporation }}{\text { Total energy given to dryer }}$ 
Or:

$\eta=\frac{T_{1}-T_{2}}{T_{1}-T_{o}}$

Where:

$\eta=$ The thermal efficiency

$T_{1}=$ The inlet air temperature

$T_{2}=$ The outlet air temperature

$T_{o}=$ The ambient air temperature

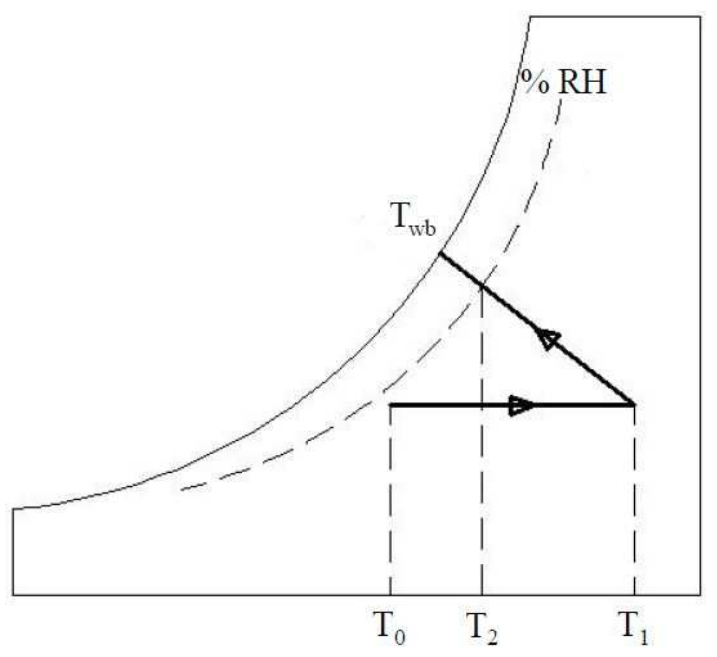

Fig. 10. Illustration of the drying process

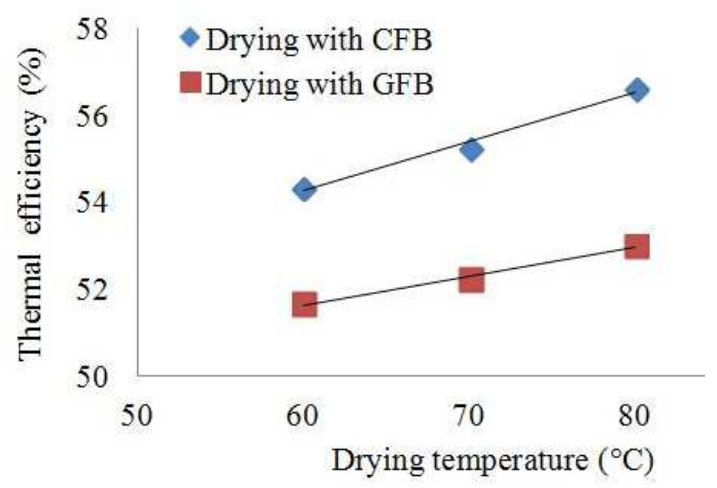

Fig. 11. Comparison of thermal efficiency

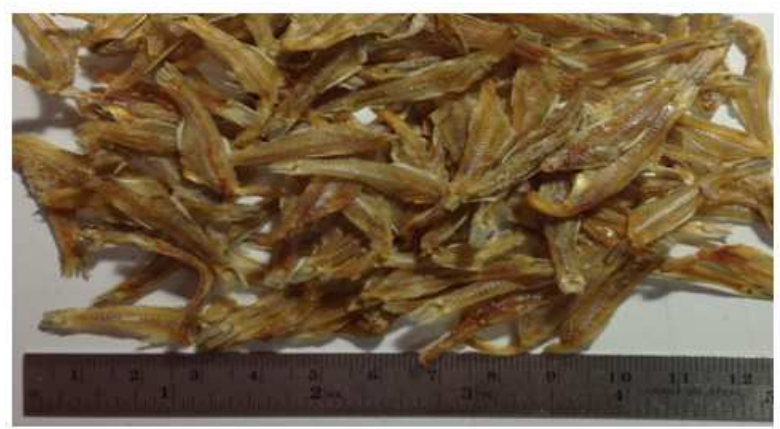

Fig. 12. The dried anchovy after drying
The maximum efficiency will occur at $T_{2}$ equals wet bulb temperature $\left(T_{w b}\right)$ at exit conditions. The drying air process was simplified in the constant enthalpy process while the temperature of the product surface equals the wet bulb temperature. Comparisons of thermal efficiency are shown in Fig. 11.

The efficiencies were fitted to the linear equation and are shown as the following Equation 10 and 11 for CFB and GFB dryers, respectively:

$$
\begin{aligned}
& \eta_{C F B}=0.1133 T+47.461 \\
& \eta_{G F B}=0.0667 T+47.639
\end{aligned}
$$

The $\mathrm{R}^{2}$ of Equation 10 and 11 are 0.988 and 0.995 , respectively; in addition, drying temperature ranges from $60-80^{\circ} \mathrm{C}$. The GFB dryer dries at higher air flow rates than the $\mathrm{CFB}$ dryer which can increase the growth of gas bubbles. If flow rates were supplied to the GFB at a velocity higher than the minimum fluidization velocity, dusty gas filling the bed could be formed into gas bubbles and affect the thermal efficiency (Dongbang et al., 2010; Nakamura and Watano, 2007).

The darkness of the anchovy at different conditions is shown in Fig. 12. The darkness of the dried anchovy by drying with GFB and CFB dryer is not different. When the drying air temperature was increased from 60 to $80^{\circ} \mathrm{C}$, the darkness was also affected adversely; notwithstanding the dried anchovy are marketable. The discoloration is caused by oxidation of carotenoid pigments at elevated temperatures (Dongbang et al., 2010; Nakamura and Watano, 2007).

\section{Conclusion}

Anchovy drying using the CFB and GFB dryer can be concluded as follows. An increase in drying temperature $\left(60-80^{\circ} \mathrm{C}\right)$ can increase the performance in evaporating the moisture. Drying with the CFB gives a shorter drying time than the GFB due to the higher heat and mass transfer coefficients. The space requirement of the CFB is low. The CFB can prevent growth of large bubbles because it can fluidize at a low velocity. The air velocity can increase to increase the fluidization; in addition, it is easier to control. The thermal efficiency of the CFB is higher than the GFB based on heat and mass transfer rates. In addition, the quality of the dried anchovy is acceptable. The Page drying model is the best model based on the highest value of $\mathrm{R}^{2}$ and the lowest value of RMSE.

\section{Acknowledgement}

The researchers wish to thank their students for recording the data and the Faculty of Engineering, 
Burapha University, Thailand for supporting the research funding i.e., "The comparison of performance of Indian anchovy drying between the gravitational and centrifugal fluidized bed technique (22/2555)".

\section{Author's Contributions}

Watcharin Dongbang: Participated in apparatus design, experiments, curve fitting, helped in the analysis and interpretation of data and wrote the manuscript.

Rungtawan Wiwattanasirikul: Provided the research idea/plan, helped in the analysis and interpretation of data and provided critical review of the manuscript.

\section{Ethics}

This article is original and contains unpublished material. The corresponding author confirms that all of the other authors have read and approved the manuscript and no ethical issues are involved.

\section{References}

AOAC, 1998. AOAC Official Methods of Analysis. 16th Edn., AOAC International, Gaithersburg, USA.

Basilone, G., K. Ganias, R. Ferreri, M. D'Elia and E.M. Quinci et al., 2015. Application of GAMs and multinomial models to assess the spawning pattern of fishes with daily spawning synchronicity: A case study in the European anchovy (Engraulis encrasicolus) in the central Mediterranean Sea. Fisheries Res., 167: 92-100. DOI: 10.1016/j.fishres.2015.01.017

Chok, V.S., A. Gorin and H.B. Chua, 2010. Minimum and complete fluidization velocity for sand-palm shell mixtures, part II: Characteristic velocity profiles, critical loading and binary correlations. Am. J. Applied Sci., 7: 773-779. DOI: 10.3844/ajassp.2010.773.779

Chungcharoen, T., S. Prachayawarakorn, P. Tungtrakul and S. Soponronnarit, 2014. Effects of germination time and drying temperature on drying characteristics and quality of germinated paddy. Food Bioproducts Proc. DOI: $10.1016 /$ j.fbp.2014.09.013
Dongbang, W. and A. Matthujak, 2013. Anchovy drying using infrared radiation. Am. J. Applied Sci., 10: 353-360. DOI: 10.3844/ajassp.2013.353.360

Dongbang, W., W. Pirompugd and K. Triratanasirichai, 2010. The drying kinetics of chilies using a rotating fluidized bed technique. Am. J. Applied Sci., 7: 1599-1606. DOI: 10.3844/ajassp.2010.1599.1606

Ghaly, A.E. and K.N. MacDonald, 2012. Mixing patterns and residence time determination in a bubbling fluidized bed system. Am. J. Eng. Applied Sci., 5: 170-183. DOI: 10.3844/ajeassp.2012.170.183

Marina, C. and I.Y. Maria, 2013. Modeling the effect of temperature and lipid content on anchovy (Engraulis anchoita) salting kinetics. J. Food Eng., 115: 164-172. DOI: 10.1016/j.jfoodeng.2012.10.004

Mujumdar, A.S., 2000. Drying Technology in Agriculture and Food Sciences. 1st Edn., Science Publishers, ISBN-10: 1578081483, pp: 313.

Nakamura, H. and S. Watano, 2007. Numerical modeling of particle fluidization behavior in a rotating fluidized bed. Powder Technol., 171: 106-117. DOI: $10.1016 /$ j.powtec.2006.08.021

Rieck, C., T. Hoffmann, A. Buck, M. Peglow and E. Tsotsas, 2015. Influence of drying conditions on layer porosity in fluidized bed spray granulation. Powder Technol., 272: 120-131. DOI: $10.1016 /$ j.powtec.2014.11.019

Sau, D.C., S. Mohanty and K.C. Biswal, 2007. Minimum fluidization velocities and maximum bed pressure drops for gas-solid tapered fluidized beds. Chem. Eng. J., 132: 151-157. DOI: 10.1016/j.cej.2007.01.036

Travis, S., A. Al-Qaraghuli and L.L. Kazmerski, 2013. A comprehensive review of the impact of dust on the use of solar energy: History, investigations, results, literature and mitigation approaches. Renewable Sustainable Energy Rev., 22: 698-733. DOI: $10.1016 /$ j.rser.2012.12.065

Triratanasirichai, K., W. Dongbang and W. Pirompugd, 2011. Mathematical modeling of drying characteristics of chilies in a rotating fluidized bed technique. Am. J. Applied Sci., 8: 979-983. DOI: 10.3844/ajassp.2011.979.983

Zhu, A. and X. Shen, 2014. The model and mass transfer characteristics of convection drying of peach slices. Int. J. Heat Mass Trans., 72: 345-351. DOI: 10.1016/j.ijheatmasstransfer.2014.01.001 